\title{
2011 Annual Report of the Poison Control Centre of Ain Shams University Hospital, Cairo, Egypt
}

\author{
Mohy K. El Masry and Hany M. Tawfik ${ }^{1}$
}

${ }^{1}$ Poison Control Center, Ain Shams University Hospitals, Cairo, Egypt

\begin{abstract}
Background: Poisoning is a growing public concern and real potential threat to the Egyptian community. The Poison Control centre (PCC), Ain Shams University, the first and larger in Egypt and the Middle East managed and treated more than 21.000 patients on the year 2011.

The aim of the study is to highlight the profile of poisoning in Poison Control Center Ain Shams University (Egypt) to facilitate the recognition of the different threats to which the Egyptian community is exposed.

Methods: Computerized data of a specially designed program comprised demographic in addition to clinical and management data of the poisoning cases received in PCC on the year 2011. A descriptive analysis and statistics of the medical records is accomplished.

Results: Overall, 21.550 poison exposure cases were recorded. Children under 7 years old were involved in $23.9 \%$ of cases, patients at group of age $15-40$ years involved in $62.8 \%$. In $49 \%$ of patients, the poisoning was deliberate. Attempted suicide was definitely more common in females and started as early as the pubertal age. Substances most frequently involved were food poisoning, organophosphate, cleaning products and tramadol that almost doubled yearly over the last few years. Clinical severity was mild in $75.1 \%$ of cases, $20.7 \%$ was moderate and $4.2 \%$ was severe. Sixty one fatalities were recorded. Management of these cases was described

Conclusions: Specific attention has been drawn towards attempted suicide in adolescents and early adulthood, the younger age of drug users and the progressive increase of some of drugs of abuse and the changing pattern of poisoning over years.
\end{abstract}

\section{Introduction}

$\mathrm{P}$ oisoning exposure is an increasingly public concern due to the progressive flooding of chemicals, pharmaceuticals and natural toxins in the international markets and people agglomerations. Factors enhancing this poisoning epidemic expansion are multiple and complex in any country. Poison Control Centre (PCC) is witnessing a continuously changing poisoning pattern closely reflecting the changing industry, economy, and social configurations. The wide availability of chemicals and medications has led to increased exposure of humans to potential poisons. An unavoidable result has been an increase in the number of poisonings - a leading cause of injuryrelated fatalities (Clark, 2004).

Since the beginning of the twentieth century industrialization and technological advancement have resulted in an exponential growth in the number of chemicals introduced into the environment, workplace and home. These include medications, complementary medicine products, cleaning substances, pesticides, fertilizers, petroleum distillates, intermediates in chemical processes, and drugs of abuse (Wax, 2006).

The information released by the poison control centre has always been a trigger for laws and regulations revision and a warning for an increasing hazard challenging the community.

Despite the continuous update of information on poisons and intoxications, several problems have yet to be resolved: a) there is still insufficient awareness regarding the potential hazards of poisons, b) physicians are still not adequately trained in clinical toxicology, and c) keeping pace with the increasing amount of information has not always been possible due to its huge volume, limited availability and insufficient clinical exposure (Hoffman, 2007).

\section{Aim of the work}

The objective of this study is to help identify the magnitude of poisoning and its patterns. Interpretation of the poisoning data through an annual report would be essential to face continuously challenging hazards 
of variable magnitude and appearance. Analysis of data on the epidemiology of poisoning and poison exposures in an annual report will enable us to issue warning reports and invite the health authorities to advocate steps towards preventive regulations for the welfare of for the community.

\section{Methods}

The total number of poisoning cases and environmental toxic exposures amounted to 21.550 patients over a 12 month period (from start of January 2011 to end of December 2011). This number represents the actual poisoning cases referred to the Poison Control Centre in Ain Shams University Hospitals, from different governmental, private hospitals and medical centres in the region. The demographic and clinical management data collected throughout the study period were tabulated and statistically analysed.

The clinical severity of each case was graded according to previously published criteria (Persson et al., 1998) as mild (e.g., minimal, self-limited); moderate (e.g., systemic, more pronounced and prolonged than minor manifestations but not life threatening); and severe (e.g., life-threatening manifestations, significant disability).

In addition, each case was classified according to drug, non-drug and unknown. The drugs include various types of drugs available in Egypt and include also drug of abuse agents. The non-drug involved food poisoning, chemicals, biological (poisonous plants and venomous animals), gases, metals and miscellaneous agents.

\section{Results}

Age and sex distribution revealed that the largest poisoning affection was at the age group of 15 25 years accounting for $39 \%$ of total cases with female preponderance, followed by the age group $<7$ with male predominance (Table 1).

Most of cases originated from greater Cairo $(69 \%)$ followed by the nearby Kalioubeya (15.5\%) and Guiza (12.4\%) governorates (Table 2). Referral from other general, private hospitals or clinics was documented in $3 \%$ of cases.

Route of poisoning was mostly oral in $94.9 \%$ of cases. Other routes included inhalation in $2.7 \%$ of cases, bites and stings in $2.2 \%$, dermal route in $0.1 \%$, and injection in $0.1 \%$ of cases (Table 3 ).

Study of the mode of poisoning disclosed attempted suicide in $49 \%$ of the cases. Accidental mode of poisoning was next in frequency and accounted for $42.7 \%$ of cases followed by drug overdose in $7.5 \%$, therapeutic error in $0.4 \%$ and criminal cause in $0.4 \%$ of cases (Table 4). Moreover $73 \%$ of the attempted suicide was in female and $69 \%$ was at the age between 15 - 40 years. Alarming figures revealed attempted suicide in 450 patients between 10 to $>15$ years of age mostly female $(77 \%$ of those who attempted suicide in this age group). On the other hand 5021 out of 5150 cases $(97.5 \%)$ of the age group below 7 years of age were caused by accidental exposures.

Pharmaceuticals were responsible for $46.7 \%$, non-drugs chemicals and environmental hazards represented $45.3 \%$ while in $8 \%$ of cases, poisoning was of unknown etiology (Table 5).

The most frequently involved drug was tramadol (responsible for $7.4 \%$ of the total poisoning cases), followed by theophylline (4.2\%), antibiotics (3.7\%), NSAIDs (3.6\%), paracetamol (2.9\%) and benzodiazepine (2.9\%) (Table 6). Tramadol was responsible for 176 children less than 15 years of age (11\% of all tramadol cases). It was responsible for 706 intoxications in the age group between 15 and $<25$ years (44.2\% of all tramadol cases). Unexpected results revealed that $29.8 \%$ (90 out of 302 cases) of cannabis intoxication occurred in the age group below 2 years of age.

Amongst the non-drug poison, the highest percentage was related to food poisoning (14\%), while organophosphate and carbamate insecticides constituted $11 \%$, followed by corrosive $(6.5 \%)$, and zinc phosphide (3\%) (Table 7). Agents most frequently involved in children $<7$ years, were corrosive $(18 \%)$, organophosphate $(14 \%)$ and detergents $(13 \%)$ (Table 8).

Poisoning severity was mild in the majority $(75.1 \%)$ of cases, moderate in $(20.7 \%)$ and severe in (4.2\%) (Table 9).

Death occurred in sixty one cases $(0.3 \%)$. The leading cause of death was organophosphate (20 cases), followed by tramadol (9 cases), corrosive (4 cases) and methanol (3 cases). The other causes of death from different poisons are displayed in (Table 10). One third of all cases died within the first day. In another third of cases, death supervened after a prolonged period of stay more than 5 days underlying an irreversible cause of death as brain stem death in the majority.

Period of hospitalisation was less than 6 hours for the largest number of patients $(75.1 \%)$ reflecting the mild severity of poisoning. In $18.2 \%$ of patients the period of stay was $6-24 \mathrm{~h}$, in $4.6 \%$ of the patients was from 1-2 days and in $2.1 \%$ it extended more than 2 days (Table 11).

Decontamination procedures were accomplished on $32.6 \%$ of cases either in the form of gastric lavage or ipecac emesis. Enhanced elimination in the form of activated charcoal was administered for $10.1 \%$ while hemodialysis was the mainstay treatment of 23 cases, half of them were due to severe theophylline toxicity. Antidotes treatment accounted for $4.3 \%$ of cases. Mechanical ventilation was needed in $14.8 \%$ of the ICU cases and $73 \%$ of them required the application of PEEP ventilation. Emergency and supportive treatments and other various therapies and interventions recommended by the PCC are displayed in the (Table12). 
Table 1: The age and gender distribution of poisoned cases received in PCC through the year 2011.

\begin{tabular}{|l|c|c|c|c|c|c|}
\hline \multirow{2}{*}{ Age (years) } & \multicolumn{2}{|c|}{ Male } & \multicolumn{2}{c|}{ Female } & \multicolumn{2}{c|}{ Total } \\
\cline { 2 - 7 } & No & \% & No & \% & No & \% \\
\hline$<7$ & 2931 & $13.6 \%$ & 2220 & $10.3 \%$ & 3150 & $23.9 \%$ \\
\hline $7-<15$ & 582 & $2.7 \%$ & 711 & $3.3 \%$ & 1314 & $6.1 \%$ \\
\hline $15-<25$ & 2931 & $13.6 \%$ & 5646 & $26.2 \%$ & 8555 & $39.7 \%$ \\
\hline $25-40$ & 2478 & $11.5 \%$ & 2500 & $11.6 \%$ & 4978 & $23.1 \%$ \\
\hline$>40$ & 840 & $3.9 \%$ & 711 & $3.3 \%$ & 1553 & $7.2 \%$ \\
\hline Total & 9762 & $45.3 \%$ & 11788 & $54.7 \%$ & 21550 & $100 \%$ \\
\hline
\end{tabular}

Table 2: The Residence of poisoned cases received in PCC through the year 2011.

\begin{tabular}{|l|c|c|}
\hline \multicolumn{1}{|c|}{ Region } & No & $\%$ \\
\hline Cairo & 14870 & $69 \%$ \\
\hline Kalioubeya & 3340 & $15.5 \%$ \\
\hline Giza & 2672 & $12.4 \%$ \\
\hline Other Delta Governorates & 237 & $1.1 \%$ \\
\hline Upper Egypt Governorates & 237 & $1.1 \%$ \\
\hline Suez Canal Governorates & 151 & $0.7 \%$ \\
\hline Unknown & 43 & $0.2 \%$ \\
\hline Total & 21550 & $100 \%$ \\
\hline
\end{tabular}

Table 3: The routes of poisoning of poisoned cases received in PCC through the year 2011.

\begin{tabular}{|l|c|c|}
\hline \multicolumn{1}{|c|}{ Route } & No & \% \\
\hline Ingestion / Oral & 20450 & $94.9 \%$ \\
\hline Inhalation / nasal & 582 & $2.7 \%$ \\
\hline Bite / sting & 474 & $2.2 \%$ \\
\hline Dermal / skin-scalp & 22 & $0.1 \%$ \\
\hline Injection & 22 & $0.1 \%$ \\
\hline Total & 21550 & $100 \%$ \\
\hline
\end{tabular}

Table 4: Mode of poisoning of poisoned cases received in PCC through the year 2011.

\begin{tabular}{|l|c|c|}
\hline \multicolumn{1}{|c|}{ Mode } & No & \% \\
\hline Suicidal & 10559 & $49 \%$ \\
\hline Accidental & 9202 & $42.7 \%$ \\
\hline Overdose drug of abuse & 1616 & $7.5 \%$ \\
\hline Criminal & 86 & $0.4 \%$ \\
\hline Therapeutic error & 87 & $0.4 \%$ \\
\hline Total & 21550 & $100 \%$ \\
\hline
\end{tabular}

Table 5: Type of causative agents of poisoned cases received in PCC through the year 2011.

\begin{tabular}{|l|c|c|}
\hline \multicolumn{1}{|c|}{ Type } & No & \% \\
\hline Drugs & 10064 & $46.7 \%$ \\
\hline Non- drug & 9762 & $45.3 \% \%$ \\
\hline Unknown & 1724 & $8 \%$ \\
\hline Total & 21550 & $100 \%$ \\
\hline
\end{tabular}


Table 6: Drugs involved in poisoned cases received in PCC through the year 2011.

\begin{tabular}{|l|c|c|l|c|c|}
\hline \multicolumn{1}{|c|}{ Drug } & No & $\%$ & \multicolumn{1}{c|}{ Drug } & No & \% \\
\hline Tramadol & 1595 & $7.4 \%$ & Oral contraceptive & 172 & $0.8 \%$ \\
\hline Theophylline & 905 & $4.2 \%$ & Antihypertensives & 172 & $0.8 \%$ \\
\hline Antibiotics & 797 & $3.7 \%$ & Vitamins & 129 & $0.6 \%$ \\
\hline NSAIDs & 776 & $3.6 \%$ & Digoxin & 129 & $0.6 \%$ \\
\hline Paracetamol & 625 & $2.9 \%$ & Unknown drug & 87 & 0.4 \\
\hline Benzodiazepine & 625 & $2.9 \%$ & Opiate & 65 & $0.3 \%$ \\
\hline Carbamazepine & 431 & $2 \%$ & Ca channel blocker & 58 & $0.27 \%$ \\
\hline Neuroleptic & 431 & $2 \%$ & Parkinol & 44 & $0.2 \%$ \\
\hline Beta Blockers & 302 & $1.4 \%$ & Diuretic & 43 & $0.2 \%$ \\
\hline Cannabis & 302 & $1.4 \%$ & Valproate & 44 & $0.2 \%$ \\
\hline Oral hypoglycemic & 280 & $1.3 \%$ & Muscle relaxant & 22 & $0.1 \%$ \\
\hline Metformin & 237 & $1.1 \%$ & Phenytoin & 19 & $0.09 \%$ \\
\hline Salicylate & 237 & $1.1 \%$ & Insulin & 17 & $0.08 \%$ \\
\hline Antihistaminics & 216 & $1 \%$ & Serotonin Reuptake Inhibitors & 13 & $0.06 \%$ \\
\hline cyclic antidepressant & 213 & $0.99 \%$ & Miscellaneous drugs & 1078 & $5 \%$ \\
\hline Total & \multicolumn{2}{|c|}{10064} & & $46.7 \%$ & \\
\hline
\end{tabular}

Table 7: Non-drug most frequently involved in poisoned cases received in PCC through the year 2011.

\begin{tabular}{|l|c|c|}
\hline \multicolumn{1}{|c|}{ Type } & No & $\mathbf{( \% )}$ \\
\hline Food poisoning & 3017 & $14 \%$ \\
\hline Ciguatera & 147 & $0.7 \%$ \\
\hline Tetrodotoxin & 4 & $0.02 \%$ \\
\hline Organophosphate insecticide & 2112 & $9.8 \%$ \\
\hline Carbamate insecticide & 259 & $1.2 \%$ \\
\hline Corrosives & 1400 & $6.5 \%$ \\
\hline Zinc and aluminium Phosphide & 646 & $3 \%$ \\
\hline Kerosene and petroleum. distillate & 624 & $2.9 \%$ \\
\hline Detergents & 108 & $0.5 \%$ \\
\hline Phenol & 86 & $0.4 \%$ \\
\hline Carbon Monoxide & 323 & $1.5 \%$ \\
\hline Hydrogen sulphide & 4 & $0.02 \%$ \\
\hline Paint & 6 & $0.03 \%$ \\
\hline Paraphenylenediamine dye & 11 & $0.05 \%$ \\
\hline Alcohol (Ethanol) & 302 & $1.4 \%$ \\
\hline Methanol & 17 & $0.08 \%$ \\
\hline Animal poisoning & 474 & $2.2 \%$ \\
Scorpion & 194 & $0.9 \%$ \\
Snake & 172 & $0.8 \%$ \\
Spider sting & 1 & $0.005 \%$ \\
Unknown stings & 107 & $0.5 \%$ \\
\hline Metals & 49 & 0.23 \\
Iron & 43 & $0.2 \%$ \\
Lead & 6 & $0.03 \%$ \\
\hline Plants and herbals & 18 & $0.08 \%$ \\
\hline Lachrymatory agent (Riot control) & 21 & $0.1 \%$ \\
\hline Miscellaneous & 112 & $0.5 \%$ \\
\hline Total & 9762 & $45.3 \%$ \\
\hline
\end{tabular}

Table 8: Poisons most frequently involved in 5150 children $<7$ years age received in PCC through the year 2011.

\begin{tabular}{|l|c|c|}
\hline \multicolumn{1}{|c|}{ Agents } & Number & $\%$ \\
\hline Corrosive & 927 & $18 \%$ \\
\hline Organophosphate & 721 & $14 \%$ \\
\hline Hydrocarbon \& Detergents & 670 & $13 \%$ \\
\hline
\end{tabular}


Table 9: Grading of poisoning severity of cases received in PCC through the year 2011 (Persson et al., 1998).

\begin{tabular}{|l|c|c|}
\hline Degree of severity & No & $(\boldsymbol{\%})$ \\
\hline Mild & 16184 & $75.1 \%$ \\
\hline Moderate & 4461 & $20.7 \%$ \\
\hline Severe & 905 & $4.2 \%$ \\
\hline Total & 21550 & $100 \%$ \\
\hline
\end{tabular}

Table 10: Death-related offending agents.

\begin{tabular}{|l|c|l|c|}
\hline \multicolumn{1}{|c|}{ Agent } & No & \multicolumn{1}{c|}{ Agent } & No \\
\hline Organophosphate & 20 & Unknown & 2 \\
\hline Tramadol & 9 & Neuroleptics & 1 \\
\hline Methanol & 3 & Scorpion & 1 \\
\hline Corrosive & 4 & Theophylline & 1 \\
\hline Carbon Monoxide & 4 & Digoxin & 1 \\
\hline Phosphide & 3 & Tetrodotoxin & 1 \\
\hline Cyanamide (Dormex) & 2 & Salicylate & 1 \\
\hline Benzodiazepine & 2 & Neuroleptic Malignant S. & 1 \\
\hline Kerosene & 2 & Snake bite & 1 \\
\hline Paraphenylenediamine dye & 2 & & \\
\hline Total & 61 & & \\
\hline
\end{tabular}

Table 11: The period of hospitalisation of poisoned cases received in PCC through the year 2011.

\begin{tabular}{|l|c|c|l|c|c|}
\hline Period of hospitalization & No & $(\%)$ & Period of hosp. & No & $(\%)$ \\
\hline$<6 h$ & 16184 & $75.1 \%$ & $4-<5 d$ & 22 & $0.1 \%$ \\
\hline $6 h-24 h$ & 3922 & $18.2 \%$ & $5-<6 \mathrm{~d}$ & 13 & $0.06 \%$ \\
\hline $1 \mathrm{~d}-<2 \mathrm{~d}$ & 991 & $4.6 \%$ & $6-<7 \mathrm{~d}$ & 9 & $0.04 \%$ \\
\hline $2 \mathrm{~d}-<3 \mathrm{~d}$ & 281 & $1.3 \%$ & $>7 \mathrm{~d}$ & 64 & $0.3 \%$ \\
\hline $3 \mathrm{~d}-<4 \mathrm{~d}$ & 64 & $0.3 \%$ & & & \\
\hline \multicolumn{7}{|c|}{ Total } & 21550 & $100 \%$ \\
\hline
\end{tabular}

Table 12: Interventions offered to acutely poisoned cases received in PCC through the year 2011.

\begin{tabular}{|l|c|l|c|}
\hline \multicolumn{1}{|c|}{ Type of intervention } & No & \multicolumn{1}{c|}{ Type of intervention } & No \\
\hline \multicolumn{1}{|c|}{ Decontamination (32.6\%) } & \multicolumn{1}{c|}{ Supportive treatment } & 67 \\
\hline Ipecac Emesis & 5178 & Ambu Resuscitation & 1309 \\
\hline Gastric lavage & 1844 & Oxygen & 301 \\
\hline Enhanced elimination (10.3\%) & Endotracheal intubation & $\mathbf{5 3 0}$ \\
\hline Activated charcoal & 2190 & Airway suction & 134 \\
\hline Hemodialysis & 23 & \multicolumn{1}{c|}{9} \\
\hline Peritoneal dialysis & 2 & Mechanical Ventilation & 58 \\
\hline \multicolumn{2}{|c|}{ Antidote 929 (4.3\%) } & Mechanical Ventilation + Positive end expiratory pressure & 9502 \\
\hline Atropine & 640 & IVF and Electrolytes & 1234 \\
\hline Obidoxime & 277 & H2 Blockers & 1008 \\
\hline Naloxone & 97 & Antibiotics & 793 \\
\hline Bicarbonate & 81 & Antiemetic & 411 \\
\hline N-acetylcysteine & 46 & Steroids & 369 \\
\hline Dextrose 25\% & 41 & Sedative hypnotics & 128 \\
\hline Scorpion anti-venoms & 36 & Nebulizer therapy & 112 \\
\hline Snake anti-venoms & 33 & Mannitol & \\
\hline Ethanol & 12 & \\
\hline Flumazenil & 10 & & \\
\hline Calcium gluconate & 10 & & \\
\hline Hyperbaric O2 therapy & 5 & & \\
\hline Methylene blue & 4 & & \\
\hline Glucagon & 3 & & \\
\hline
\end{tabular}

\section{Discussion}

The PCC of Ain Shams University is the first and largest national poison treatment centre of Egypt. The annual report of the year 2011 describes a total number of 21.550 poisoned patients managed and treated in the centre.

The results of the collected data revealed that $62.8 \%$ of poison exposures were at the age $15-40$ years 
while $23.9 \%$ of poison exposures were children under 7 years. The lowest incidence of poisoning was at age group $7-<15$ years $(6.1 \%)$ and over 40 years $(7.2 \%)$ (Table1). The high incidence of poisoning in the early adulthood and middle age deserve particular attention. This poisoning prone age group is subject to tremendous emotional and economic challenges in Egypt. Compared to other countries whether of Arabic or western culture revealed that the greater majority of poisoning cases usually lie in the age group below 5 years of age. The 2010 annual report of the American Association of Poison Control Centres revealed that children under age of 5 make up to $51 \%$ of all poison exposures (Alvin et al., 2011). The Saudi Arabia Report of acute chemical poisoning during the first six months of year 2004 revealed that the highest proportion of acute poisoning was observed among children $\leq 5$ years of age (Moazzam et al., 2004). These observations strongly point to economic defies affecting principally the most vulnerable and conscious age group in Egypt. Other factors include interlinked emotional, social, financial and conjugal stresses.

The residence data revealed that most of cases originated from Cairo (69\%) followed by Kalioubeya and Giza where they represented $15.5 \%$, and $12.4 \%$ respectively. This is attributed to the proximity of these governorates to the PCC and not to the higher magnitude of the poisoning health problem. (Table 2).

The data result revealed that the oral route was the most common route of poisoning (94.9\%) (Table 3). Andiran and Sarikayalar on 2004 found that the oral route was the most common route of poisoning and this agreed as well with results of other studies in Saudi Arabia and those issued in the 2010 annual report of the American Association of Poison Control Centres (79.5\%).

It is evident from this study that attempted suicide $(49 \%)$ exceeded accidental $(42.7 \%)$ poisoning exposure (table 4). Most of attempted suicide was induced by females (73\%). This incidence of suicide is even higher $(69 \%)$ in the age group 15-40years. A more alarming figure is the attempted suicide among the pubertal development age (10 $-<15$ years), the large majority of which $(77 \%)$ are girls. These results are in accord with Goksu, 2002 who found that most attempted suicide poisoning cases were among teenagers and young adults, females significantly outnumber males and drugs were commonly the mode of intentional poisoning. In contrast, the 2010 annual report of the American Association of PCCs found that only $14.7 \%$ of poisoning was intentional (Alvin et al., 2011). Despite the strong religious morals in Islam and Christianity that ban self-destruction and deliberate self-killing, yet young adults seem not immune to the attempted suicide.
Children of preschool age (<7years) particularly male, were subjected to poisoning accidents $(23.9 \%)$ more than any other age group, this can be attributed to the particular behaviour of that age group as curiosity, oral identification, discrimination inability and taste and smell immaturity. These results were similar to those of Andiran and Sarikayalar 2004 where they found that accidental poisoning was commonest amongst children and remains a significant problem for this age group.

The collected data revealed that $46.7 \%$ of the cases were due to drug poisoning and $45.3 \%$ was nondrugs poisoning (table 5), bearing a great resemblance to the data issued in the Annual Report of 2010 of the American Association of Poison Control Centres. The four most frequently involved groups of substances in all poison exposures were food poisoning (14\%), organophosphate $(9.8 \%)$, tramadol $(7.4 \%)$ and corrosive $(6.5 \%)$ (Table 6, 7) affirming different Egyptian compared to American profile of poisoning. In the United States, analgesics (11.5\%) followed by cosmetics /personal care products $(7.7 \%)$, household cleaning substances (7.3\%), and sedatives/hypnotics/ antipsychotics $(6.0 \%)$ formed the highest poisoning frequency. Although the percentage of food poisoning was relatively high $(14 \%)$, yet it does not reflect the real magnitude of the problem as food poisoning patients, apart ciguatera, tetrodotoxin and botulism, are not referred to PCC. The vast majority of the food poisoning cases were clinically of toxigenic type. The majority of cases were managed in the emergency rooms and released for a home treatment after a period of observation of 6 to 24 hours.

An alarming figure has been the progressive rise of tramadol overdose amounting to 1595 cases in the year 2011 compared to 386 cases in 2009 and 760 cases in 2010. These data and daily observations of the magnitude of the problem enabled the PCC Ain Shams to declare new recommendations concerning drug of abuse screening list and issue several warnings in media that were given much concern by the health and drugs of abuse authorities.

Exposure to animal stings and bites were of relatively low percentage in the present study (2.2\%). Almost a third of snake bite originated from Guiza, Bahareya oasis (all viperidae type), a third from close governorates (mainly elapidae type) and the last third from greater Cairo. Scorpion stings most serious clinical presentation was in the children groups. They mainly originated from suburban, rural areas and growing new cities that invade the territories of scorpions and snakes. Despite the severity of animal exposure, the outcome was relatively satisfactory with a mortality of $0.5 \%$. This was attributed to the availability of anti-venom and strict guidelines 
concerning these exposures emergencies in our centre and non-aggressive species especially in scorpion. A smaller mortality is declared in the 2010 annual report of the American Association of PCC (0.027\%) amounting to 17 cases while it was much higher in Mexico; 1000 deaths from scorpion stings occurring per year (Bush and Charles, 2003).

The recorded mortality rate in our series was considered comparatively low $0.3 \%$ (Table 9). Shadnia, 2007 found that mortality rate in Tehran 2003 was $1.3 \%$ in the study conducted in the Islamic Republic of Iran. Another report from Saudi Arabia, 1999-2003 revealed a mortality rate of $2.2 \%$ (Moazzam et al., 2004). In contrast, the 2010 annual report of the American Association of PCCs revealed that out of 2,384,825 cases, they had 1730 deaths $(0.07 \%)$ (Alvin et al., 2011). However, this report included non-attending, trivial therapeutic accidents and information-seeking cases reported through telephone calls and not only symptomatizing referred poisoning cases, making the comparison unacceptable. The large percentage of organophosphate poisoning, the relatively high severity and necessity for ICU treatment, the relatively high frequency of mechanical ventilation and the large number of fatalities (Table 10) make the organophosphate problem of particular importance to the health care system, and invite for more rigid regulations concerning its misuse.

Decontamination procedures and activated charcoal were the most frequent procedures undertaken for poisoning cases. Antidotes followed in frequency of use. The most frequently used antidote was atropine and obidoxime reflecting the large number of received organophosphate poisoning cases. Mechanical ventilation was a common tool in ICU admitted serious cases $30 \%$ of which were due to organophosphrous poisoning and $16 \%$ due to tramadol overdose reflecting the severity grade of these types of poisoning (Table 12). The cost of management of organophosphate and tramadol, as evident from the above figures, are evaluated as great and incapacitating resources and budget of health care service for these specific intoxications.

Compared to total number of patients in PCC on 2005 (Gamalludin et al., 2006), a substantial decrease of the total annual number was evident on 2011, essentially due to the curfew regulations imposed by the armed forces for several months on different occasions after the 2011, January revolution. A significant decrease of organophosphate intoxications from $17 \%$ on 2005 to $9.8 \%$ on 2011 reflects the efforts triggered by PCC Ain Shams University, Media and Ministry Of Health to restrict the widespread use of these chemicals. On the other hand a significant rise of drug overdose was noted mainly due to the progressive dissemination of tramadol.

Another impressing finding is the methanol poisoning decreased mortality rate by about $75 \%$ due to the state's tighter control against alcoholic beverages adulteration.

\section{References}

Alvin C, Daniel A, Louis R et al. (2011): 2010 Annual Report of the American Association of Poison Control Centers' National Poison Data System (NPDS): $28^{\text {th }}$ Annual Report. Clinical Toxicology, 49, 910-941

Andiran N and Sarikayalar F (2004): Pattern of acute poisonings in childhood in Ankara, what has changed in 20 years? Turkish Journal of Pediatrics, 46(2):147-52.

Bush S and Charles G (2003): Scorpion envenomations. emedicine Available online at:

http://www.emedicine.com/emerg/topic524.ht $\mathrm{m}$

Clark R (2004): The practice of medical toxicology. In: Dart RC, ed. Medical Toxicology. $3^{\text {rd }}$ edn. Philadelphia: Lippincott Williams \&Wilkins: 3-6.

Gamalludin H, EL Seddawy A, Sakr M, et al. (2006): Evaluation of cases of acute poisoning received at the poison control center of Ain Shams Universiy Hospitals During the year 2005. Ain Shams J. Forensic Med. Clin. Toxicol., Vol. VI, Jan.

Goksu S (2002): Characteristics of acute adult poisoning in Gaziantep. Journal of clinical toxicology, 40(7):833-7.

Hoffman R (2007): Understanding the limitations of retrospective analyses of poison center data. Clin Toxicol ; 45(8):943-5.

Moazzam M, Al-Saigul A, Naguib M, et al. (2004): Pattern of acute poisoning in Al- Qassim region: a surveillance report from Saudi Arabia, 1999-2003, Eastern Mediterranean Health Journal, Vol. 15, No. 4

Persson H, Sjöberg G, Haines J, et al., (1998): Poisoning severity score. Grading of acute poisoning. J Toxicol Clin Toxicol; 36(3):205.)

Shadnia S (2007): Pattern of acute poisoning in Tehran-Iran in 2003. Human \& experimental toxicology, 26(9):753-6.

Wax P (2006): Historical principles and perspectives. In: Flomenbaum NE, Goldfrank LR, Hoffman RS, Howland MA, Lewin NA, Nelson LS, eds. Goldfrank's Toxicologic Emergencies. $8^{\text {th }}$ edn. New York: McGraw-Hill. 1-17. 
الملخص العربي

التقرير السنوي لعام 2011 لمركز علاج التسمم

محتي المصري و هاني محمد توفيق1

الخلفية: التسمم هو مصدر قلق متزايد للعامة وتهديد محتمل للمجتمع المصري. مركز علاج التسمم بمستشفيات جامعة عين

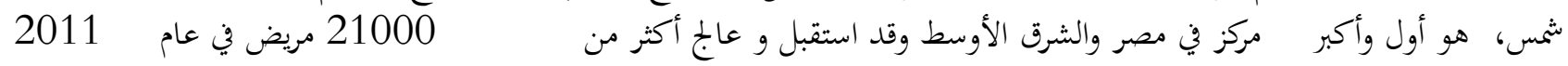

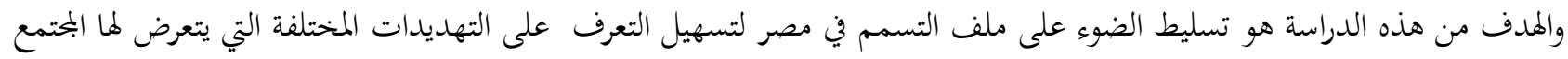
المصري.

الطرق: البيانات الموسبة لبرنامج مصمم خصيصا يحتوى على الديموغرافية، بالإضافة إلى البيانات السريرية وعلاج حالات وإحصائي من السجالات الطبية.

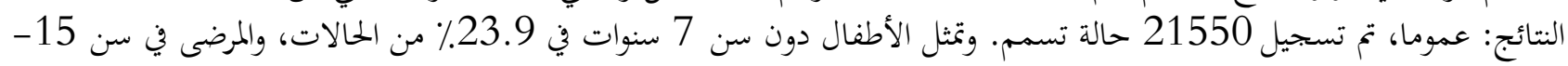

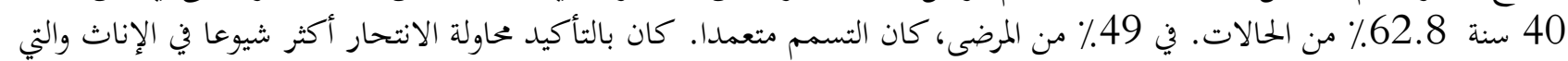

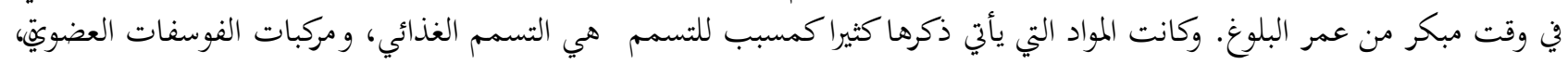

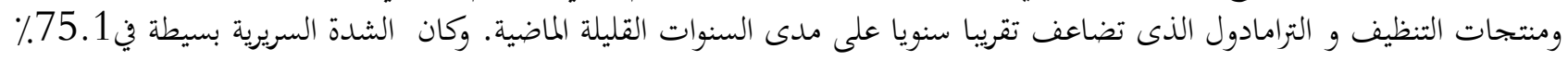

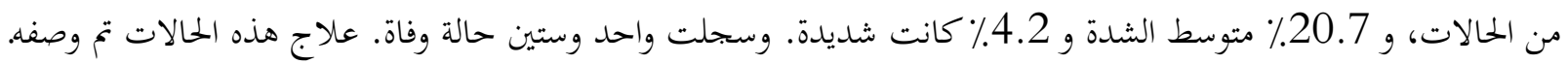

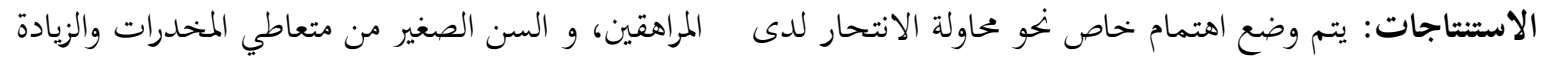

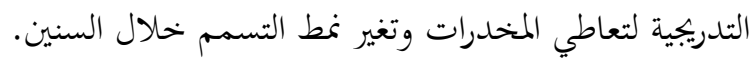

1' مركز علاج التسمم - مستشفيات جامعة عين شمس-القاهرة-مصر 